\title{
Institutos de Estudos Econômicos de Organizações Empresariais e sua Relação com o Estado em Perspectiva Comparada: Aroentina e Brasil, 1961-1996
}

Hernán Ramírez*

\begin{abstract}
Resumo: Este artigo constitui uma síntese das conclusões alcançadas em nossa tese, na qual abordamos a constituição e as formas de ação adotadas por três centros de estudos e pesquisas em economia, financiados por grupos de empresas, cujos membros mais destacados chegaram à condução econômica, ocupando postos governamentais relevantes no Brasil e na Argentina, entre os anos de 1961 e 1996. As instituições que tratamos são: o Instituto de Pesquisas Econômicas e Sociais (IPÊS), a Fundación de Investigaciones Económicas Latinoamericanas (FIEL) e a Fundación Mediterránea (FM); entidades que podem ser consideradas paradigmas de uma nova matriz de relação entre o Estado, as corporações empresariais e os técnicos vinculados fundamentalmente à área econômica desenvolvida no período.

Essas instituições contaram com uma estrutura dinâmica e atuaram como ponte para desenhar e pôr em prática políticas de transformações profundas nas estruturas
\end{abstract}

* Doutor em História pela UFRGS. Professor da UEL.

Anos 90, Porto Alegre, v. 13, n. 23/24, p.179-214, jan./dez. 2006 
Institutos de Estudos Econômicos de Organizações...

econômicas de ambos os países, afastando-se dos modelos desenvolvimentistas para se aproximarem, cada vez mais, dos moldes liberais, alcançando certo consenso no interior de diferentes frações das burguesias e de outros setores sociais.

Palavras-chave: IPÊS - FIEL - Fundación Mediterránea.

No presente artigo, pretendemos abordar as principais conclusões alcançadas em nossa tese (Ramírez, 2005), na qual realizamos uma comparação entre os principais centros de estudos e pesquisas em economia financiados por grupos de empresas que chegaram à condução da política econômica no Brasil e na Argentina, no último terço do século passado. Eles são o Instituto de Pesquisas e Estudos Sociais (IPÊS) ${ }^{1}$, para o caso brasileiro, a Fundación de Investigaciones Económicas Latinoamericanas (FIEL) e a Fundación Mediterránea (FM), que patrocina o Instituto de Estudios Económicos de la Realidad Argentina y Latinoamericana (IEERAL)2, para o caso argentino.

Devido aos objetivos específicos desta publicação, os resultados da pesquisa original são apontados, neste artigo, de uma forma na qual o trabalho historiográfico com as fontes aparece com um escasso teor de concretude, ao passo que também a descrição do contexto e de alguns conceitos não foram desenvolvidos com a amplitude merecida, privilegiando apenas aqueles que poderiam ser mais problemáticos.

A comparação foi possível, já que as estruturas e os desenvolvimentos históricos dos dois países têm diversos pontos em comum. Eles transitavam por uma etapa de esgotamento do modelo substitutivo de importações, tinham um complexo tecido social, próprio de sociedades capitalistas subdesenvolvidas, que experimentava mudanças decorrentes dessa crise, e compartilhavam processos políticos equivalentes. Nestes, incluímos interrupções do regime constitucional, com a instalação de governos civil-militares, que levaram adiante reformas estruturais, mudando radicalmente suas antigas feições, seguidas de prolongadas transições 
democráticas que precisaram fazer frente às severas crises estruturais herdadas.

Embora concordemos, em linhas gerais, com essas semelhanças nos processos vividos por Brasil e Argentina, os casos particulares apresentam algumas diferenças importantes, especialmente quanto aos períodos de existência dos institutos objeto de estudo. Para realizar uma abordagem integral dos processos, decidimos adotar uma visão ampla quanto ao período considerado, evitando, assim, o perigo de amputá-los, deixando de fora da análise questões medulares. Adotamos como datas limites aquelas que cronologicamente pudessem abranger tanto os momentos de início quanto de maturação e auge no funcionamento de todos eles. Dessa maneira, o ano de 1961, com a criação do IPÊS, abre nosso intervalo temporal que se fecha em 1996, momento da renúncia de Domingo Cavallo como ministro da Economia, data que marca o fim do apogeu da FM.

Assim, podemos englobar a história de instituições que tiveram processos mais ou menos semelhantes, ainda que com períodos de maturação diferentes. Além disso, a notada diferença no fato de que o IPÊS deixou de existir rapidamente, pôde nos ajudar a demonstrar algumas de nossas hipóteses, especialmente aquela que diz respeito à retomada de controles indiretos, após a redução dos conflitos por parte da classe dominante, e à necessidade de constituir uma estrutura forte e autônoma como garantia de sobrevivência.

Ainda que a trajetória dos três institutos tenha sido importante, exceto para o caso do IPÊS, poucos estudos específicos têm sido elaborados. Entretanto, a lista bibliográfica que os aborda tangencialmente é extensa, por isso, fazer uma análise exaustiva excede aqui nossas possibilidades. Faremos, portanto, menção a trabalhos concentrados estritamente no nosso tema.

Para o caso brasileiro, merece destaque a volumosa tese de René Armand Dreifuss (1981) a qual, além de oferecer abundante 
Institutos de Estudos Econômicos de Organizações...

evidência empírica, bebe em correntes teóricas do nosso interesse, em particular Ralph Miliband, e trata a relação entre empresários, técnicos e burocratas de forma basicamente similar à aqui proposta, estimulando, portanto, o diálogo.

Fruto de sua opção metodológica, a meticulosidade e a abundância dos dados fornecidos pelo autor são de tal magnitude que se torna difícil muitas vezes realizar contribuições novas, especialmente no período anterior a 1964, razão pela qual, apesar de vasculhar as mesmas fontes, as novidades têm sido limitadas, centrando-se estas fundamentalmente nos aportes extraídos dos balanços de 1962 e 1963 e das atas do Comitê Orientador, não indicados expressamente como fontes por Dreifuss. Posteriormente àquela data, nossas descobertas têm sido maiores e a possibilidade de realizar uma abordagem integral da vida do Instituto, diferentemente desse autor que só trabalhou uma parte, permitiu-nos ter uma perspectiva de conjunto, conferindo novos significados ao já conhecido.

Mais específicos são outros quatro trabalhos que circunscrevem sua abordagem a aspectos particulares ou lançam um olhar regional sobre as atividades do IPÊS. Assim, temos a dissertação em Pedagogia de Maria Inêz Salgado de Souza (1981), que faz uma análise pormenorizada da política educativa proposta, fundamentalmente no Fórum da Educação promovido por essa instituição. Duas dissertações em Ciência Política sob orientação de Dreifuss: a de Solange de Deus Simões (1985), que realiza um exaustivo estudo da participação das mulheres, particularmente vinculadas à Igreja, no golpe de 1964, e a de Heloisa María Murgel Starling (1986), metodologicamente semelhante à pesquisa de seu orientador e focada em Minas Gerais, com um tópico destinado à participação do segmento feminino. Por último, encontramos o livro da jornalista Denise Assis (2001), focado na análise do acervo fílmico do Instituto. 
Para os casos argentinos, as referências são menos específicas, merecendo destaque as teses do argentino Antonio Camou (1997), dirigida por Norbert Lechner, e do alemão Peter Birle (1997). Apesar de o primeiro trabalho gozar de uma bagagem empírica e teórica por momentos aparentemente irrefutáveis, sustentamos com ele divergências profundas, em particular as que se referem ao grau de autonomia outorgada à produção de idéias e à implementação de determinadas políticas públicas, derivadas em parte de sua ótica neo-institucionalista.

Com o segundo trabalho, pelo fato de bebermos em algumas vertentes teóricas comuns, as diferenças são menores, compartilhando a quase totalidade de suas hipóteses iniciais, embora não concordemos com o modo como elas são resolvidas, já que esse autor outorga demasiada importância aos acordos de cúpula, mantendo particular desacordo com aquela por ele enunciada em segundo lugar, ou seja, de que a capacidade de negociação de uma associação será tanto maior quanto mais capacidade de conflito possuam os interesses por ela representados.

Diferentemente, sustentamos uma idéia mais relativista, incluindo outros fatores nessa relação. Portanto, nosso trabalho não pretendeu derrubar essas questões, mas, em todo caso, respondêlas de outro modo, além de avançar sobre outros interrogantes que tentamos desvendar em chaves diferentes.

Recentemente, a equipe liderada por Alfredo Raúl Pucciarelli tem produzido uma interessante série de trabalhos sobre a vinculação entre empresários, tecnocratas e militares, especialmente os textos do próprio Pucciarelli e os de Mariana Heredia, Ana María Castellani e Paula Canelo, que constituem esforços preliminares de estudos mais ambiciosos, os quais têm nos ajudado com dados e na discussão teórico-metodológica acerca da forma de abordagem de nossos objetos (2004).

Finalmente, temos três textos de autores pertencentes à FIEL e à FM que, por estarem carregados de certo subjetivismo, mais 
Institutos de Estudos Econômicos de Organizações...

que obras de consulta resultam importantes fontes primárias que nos ajudam a revelar seu discurso legitimador, já que todos eles, em diferentes medidas, procuram fazer um resgate das instituições que os abrigaram beirando por momentos o laudatório.

Primeiramente, referiremo-nos ao artigo de Adolfo Sturzenegger (1994), que foi um dos mais conhecidos pesquisadores chefes da FIEL, onde relata pormenorizadamente a natureza dos trabalhos levados a cabo por essa entidade de 1984 até 1994, momento em que a organização e suas figuras principais estiveram longe do poder, exceto no intervalo que vai de 1989 a 1990, quando ascenderam ao Ministerio de Economía Miguel Roig e, após sua morte, Néstor Rapanelli. Em seu texto, expõe contribuições feitas pelos pesquisadores dessa fundação ao debate eminentemente acadêmico e político, mas não entra em análises do papel que desempenhou como um dos mais poderosos grupos de pressão existentes no país.

Em seguida, temos os trabalhos de Juan Carlos de Pablo (1994 e 1995) que também oferecem uma visão desde sua óptica de expesquisador chefe da FIEL, que para a época mostrava uma certa aproximação com Cavallo e se esforçava por escrever uma história mais simpática da instituição.

Por último, o ensaio de Enrique N’haux (1992), membro, algo marginal, da FM, oferece-nos um inestimável aporte para entendermos as tentativas de entrelaçar a história da instituição com a própria história nacional, ainda que, por momentos, o autor tenha que recorrer a procedimentos escassamente verossímeis.

Para termos uma idéia inicial da história dos institutos, podemos resumir que o IPÊS foi fundado por importantes lideranças empresariais e militares em 1961. Inicialmente ele tinha sede em São Paulo e, posteriormente, foi lançada uma seção no Rio de Janeiro, assim como entidades congêneres em outros Estados, principalmente em Minas Gerais, Paraná e Rio Grande do Sul. Esse primeiro período foi marcado pelo confronto entre as seccionais 
paulista e carioca, sendo parcialmente superado no final de 1962, quando o comando central da instituição foi dividido eqüitativamente entre representantes das duas seccionais.

A partir de então, o Instituto se lançou a desestabilizar o governo de João Goulart e a apoiar as forças opositoras, em parceria com o Instituto Brasileiro de Ação Democrática (IBAD) até 1963, proporcionando fundamentos ideológicos ${ }^{3}$ através de uma série de estudos por ele patrocinados, assim como indivíduos e aportes financeiros. Os momentos mais importantes em que atuou foram: as eleições de 1962, as discussões em torno das Reformas de Base e o plebiscito acerca do parlamentarismo, nos quais, apesar de se empenhar de corpo e alma, não alcançou os objetivos almejados.

Por esse motivo, os membros do IPÊS paulatinamente passaram a conspirar contra a ordem democrática e, embora o general Olympio Mourão Filho tenha deflagrado o golpe, seriam eles os principais herdeiros do movimento de 31 de março de 1964, colonizando muitos cargos estatais chaves e promovendo a consolidação do regime civil-militar. No entanto, pouco depois de produzido esse evento, as diferenças entre as seccionais paulista e carioca determinariam a cisão desta última para constituir o IPÊS/ Guanabara (IPÊS/GB), conservando os dois institutos uma grande vitalidade e influência no governo até 1967.

A partir dessa data, os institutos passaram por dificuldades financeiras crescentes, acompanhadas da deserção de muitos de seus membros, estendendo-se essa fase de lenta agonia até 1971, momento da desmobilização do IPÊS/GB ante a impossibilidade de proceder ao encerramento de suas atividades de acordo com seus estatutos. Apenas lhe sobreviveria o IPESUL, com sede em Porto Alegre, até data não confirmada, já que o IPÊS paulista deixara de existir pouco tempo antes, também sem poder definir o momento em que isso aconteceu. 
Institutos de Estudos Econômicos de Organizações...

A FIEL foi fundada em 1964 por quatro entidades corporativas de cúpula da burguesia Argentina. Elas eram: a Unión Industrial Argentina (UIA), a Sociedad Rural Argentina (SRA), a Cámara Argentina de Comercio (CAC) e a Bolsa de Comercio de Buenos Aires (BOLSA). Posteriormente, seriam incorporadas outras empresas como patrocinadoras e as corporações representativas dos bancos, a Asociación de Bancos de la República Argentina (ABRA) e a Asociación de Bancos Argentinos (ADEBA), passando a instituição a englobar todas as frações da alta burguesia argentina.

Entre essa data e 1975, a entidade foi definindo seus traços ideológicos mais importantes, congregando fundamentalmente intelectuais ligados ao liberalismo ortodoxo ${ }^{4}$, tendo seus membros participado amplamente dos governos constituídos após o golpe de Estado de 1966. Nessa etapa existiram, entre 1971 e 1975, algumas incorporações contraditórias nesse campo, mas elas podem ser interpretadas como adequações às dificuldades causadas pela redução do financiamento fornecido pela Fundação Ford, sua principal fonte de ingressos nesse momento, e a ascensão do peronismo, em 1973, entronizando com ele no comando da economia a Confederación General Económica (CGE), sua principal rival na época.

Superado esse período de dificuldades, entre 1976 e 1983, a entidade viveu seus anos dourados, quando membros vinculados a ela passaram a ocupar os principais cargos na área econômica nas cinco administrações militares sendo abafada toda oposição, tanto política quanto corporativa.

A redemocratização levou a FIEL a um prolongado exílio dos principais cargos governamentais, que só foi vencido em 1989, quando Carlos Menem recorreu novamente à ortodoxia econômica como solução aos problemas que ela mesma tinha causado. No entanto, esse retorno não foi hegemonizado pela instituição, que teve de enfrentar uma cisão em 1991, quando a UIA afastou-se para constituir seu próprio centro de estudos, e a concorrência de 
outras instituições, entre as quais se sobressaíram a FM e o Centro de Estudios Macroeconómicos de la Argentina (CEMA).

O IEERAL foi criado em 1977, conjuntamente com a FM, que opera como sua patrocinadora, aglutinando, em primeira instância, os médios e grandes empresários da província de Córdoba e, posteriormente, os médios e grandes empresários do interior argentino, na sua maioria vinculados ao Movimento Industrial Nacional (MIN), que opera como agrupação informal interna dentro da UIA.

Esse instituto foi antecedido pela Comisión de Estúdios Económicos y Sociales (CEES), constituída em 1969 pela Asociación de Industriales de la Provincia de Córdoba (ADIC), entidade que albergou técnicos com posturas econômicas liberais, porém consideradas heterodoxas pelos liberais ortodoxos argentinos. Durante esta etapa, vários de seus membros participaram esporadicamente dos governos militares, particularmente em momentos de crise interna, mas rapidamente sendo afastados do poder, destacando-se a incursão de Cavallo como presidente do Banco Central (BCRA) em 1982.

A partir desse evento e com maior ênfase após 1984, a FM iniciou uma etapa de expansão, com filiais nas mais importantes regiões argentinas, ainda que mantendo seu epicentro na cidade de Córdoba, motivo pelo qual teve que modificar sua estrutura, estabelecendo uma hierarquia entre seus associados, com o propósito de conservar o comando nas mãos de seus fundadores. Durante essa etapa, vários membros participam em cargos na área econômica do governo cordobês, administrado pela Unión Cívica Radical, e se levou adiante um acordo com o partido peronista, em 1987, que permitiu a Cavallo converter-se, primeiramente, em deputado e, posteriormente, em ministro de Menem, inicialmente como chanceler e, em 1991, comandando a pasta de Economia.

Desde esse momento, a FM alcançou o centro do poder na área econômica, produzindo uma vasta colonização dos aparelhos 
Institutos de Estudos Econômicos de Organizações...

estatais vinculados a ela e outros conexos. No entanto, a migração de quadros para cargos oficiais foi de tal magnitude que esvaziou a entidade dos principais técnicos, sem que conseguisse substituílos adequadamente, passando a partir de então por um período de decadência interna, que seria uma das causas da queda do próprio Cavallo.

Retornando temporalmente e passando a tratar do processo econômico em que estavam submersas as instituições, constatamos que na década de sessenta a crise do modelo substitutivo desencadeou profundas transformações nas economias brasileira e argentina, alterando algumas tendências anteriores quanto à sua matriz produtiva, provocando a concentração de alguns setores econômicos, tanto em nível das unidades produtivas quanto no regional, e conflitos sociais de ampla magnitude nos dois casos.

Essa situação gerou fortes tensões em ambos os países, envolvendo diversos grupos que, diante desse novo contexto, se encontraram imersos num extenso processo de mudanças. Nele, além de se debilitarem antigos atores sociais, entraram em cena novos grupos e se consolidaram outros, redistribuindo-se seus pesos econômico, social e político, transformando, dessa maneira, algumas das pré-condições nas quais se estabelecia o jogo econômico e político até aquele momento, num complexo processo caracterizado pelo surgimento de novos conflitos, que se sobressaíram aos acordos anteriormente realizados, dominantes durante sua fase constitutiva.

Esses conflitos sociais tomaram um renovado vigor na época e, longe de se restringir ao seu âmbito específico, as tensões excederam seus marcos respectivos, estabelecendo-se em nível político nacional de forma mais ou menos generalizada, constituindo-se como uma crise de hegemonia, segundo a perspectiva gramsciana, já que o controle da classe dominante foi contestado, sem que ela pudesse mantê-lo pela via do consenso, tendo que recorrer, em última instância, ao uso da força para restabelecê-lo. 
Uma das conseqüências mais importantes foi o aumento da heterogeneidade das associações de diversos segmentos econômicos, que passaram a competir entre si, no caso argentino, e num amplo conflito social, nos dois casos. Com o incremento da concorrência e dos conflitos entre e intraclasse, as elites ${ }^{5}$ tiveram que se organizar melhor para enfrentar os desafios que as novas circunstâncias lhes traziam. Assim, os atores com menor potencial de pressão individual viram-se na contingência de se estruturarem mais fortemente, de modo a compensar sua menor capacidade de negociação e, da mesma forma, esse reposicionamento levou também a outros setores, inclusive aqueles com potencialidade de pressão maior, a se organizarem de maneira mais sólida para contrapôlos.

Com base nessas constatações mais gerais, enunciamos como hipótese primeira desse trabalho que os setores da classe dominante tiveram a necessidade de participar ativamente na luta política. Para isso, precisaram construir organizações com estruturas mais apropriadas com as quais pudessem intervir mais convenientemente no conflito social e político, tendo no recrutamento de membros e recursos, na construção discursiva e nas novas formas de ação os pilares onde se radicou sua força.

Para dar conta dessa hipótese, temos traçado um perfil dos sócios e patrocinadores das instituições, atendendo, na medida do possível, às seguintes variáveis: localização, tamanho (expresso através de indicadores como faturamento, capital e participação nas exportações), tipo de produção, mercado ao qual se orienta e integração a grupos concentrados e/ou diversificados e outras empresas. Devemos destacar que, no caso do IPÊS, essa lista não é exaustiva, mas realizada da forma mais completa possível, levando em consideração as fontes existentes.

Igualmente, temos realizado um estudo das formas organizativas dos institutos, basicamente através da recopilação de seus estatutos e reconstrução de listas de autoridades, devido à 
Institutos de Estudos Econômicos de Organizações...

importância das minorias ativas no seio das mesmas, sobre as quais buscamos dados, atendendo a critérios prosopográficos (Heinz, 2006) mais que estritamente biográficos, já que os mesmos levaram em consideração, de maneira especial, as variáveis de origens familiares, qualificação escolar, filiação empresarial, institucional e partidária e cargos ocupados no governo.

Tendo presente que a tarefa de articulação ideológica dentro dessas organizações não é empreendida de maneira sistemática pelos empresários patrocinadores, mas sim por intelectuais especializados, confeccionamos uma lista dos pesquisadores pertencentes às instituições, sobre os quais também coletamos dados com características similares aos anteriores, enfatizando os modos de cooptação e qualificação aos quais estiveram sujeitos.

Outra das constatações à que chegamos no trabalho foi o fato de que a organização das entidades não é prévia, senão posterior ao aumento dos conflitos sociais no âmbito da sociedade civil e com o Estado. Assim, elas se constituiriam numa resposta mais do que numa antecipação frente a tais comportamentos. Além de reforçarem algumas das organizações corporativas de velho cunho, os empresários criariam outras novas, com estruturas mais apropriadas para a luta ideológica, já que aquelas demonstravam certa rigidez, difícil de ser contornada. Entre esses inconvenientes, podem ser destacados a maior exposição pública, menor coesão ideológica, derivada, em parte, de divisões internas e alta intromissão por parte do Estado.

Também corroboramos que essas organizações tenderam a recrutar uma quantidade importante de membros, para os parâmetros das classes dominantes, com características que correspondiam a grupos mais ou menos definidos, possuidores de alguma homogeneidade prévia, procurando representar em parte, mas não totalmente, a sua heterogeneidade, já que apesar desse processo sobreviveriam certas diferenças internas.

Anos 90, Porto Alegre, v. 13, n. 23/24, p.179-214, jan./dez. 2006 
$\mathrm{Na}$ continuação de nossa pesquisa, acrescentamos a essa hipótese que, embora essas organizações, durante a etapa fundacional, tenham recrutado indivíduos com características semelhantes, seus interesses não eram totalmente convergentes, existindo entre eles diferenças importantes que foram minimizadas com vistas a combater um inimigo comum, geralmente os governos populistas e a crise econômica recorrente. Contudo, uma vez vencido o inimigo principal e passando alguns de seus membros a exercer funções na implementação das políticas públicas, de onde podiam atingir interesses contrários a alguns de seus colegas de instituição, tais diferenças tornavam-se mais fortes ao aflorarem as contradições. Estas podiam desembocar tanto em cisões dentro da organização ou no afastamento de membros importantes, quanto na implementação de ações divergentes por membros de diferentes setores pertencentes a essas mesmas organizações.

Percebe-se que tanto os membros do IPÊS quanto os da FIEL faziam parte da classe dominante no momento de suas constituições, enquanto que os membros da FM ingressaram nela posteriormente, em parte como resultado do processo. Além disso, outros integrantes da FM pertencentes a essa classe foram recrutados à medida que ascendiam socialmente, o que fez com que ocorresse uma mudança considerável no perfil, tanto da instituição quanto de seus membros, entre um extremo e outro de seu percurso histórico.

Constatamos também que as frações de classe eram diferentemente representadas dentro dessas organizações. Enquanto a FM priorizava a inclusão em seu núcleo dirigente apenas de membros da fração industrial, ainda que com algumas poucas exceções, o IPÊS e a FIEL apresentaram uma abrangência maior que, no caso brasileiro, só deixou de fora os interesses das oligarquias agropecuárias, opostas a iniciativas modernizantes, inclusive as mais moderadas, promovidas pelo Instituto. 
Institutos de Estudos Econômicos de Organizações...

Assim, a forma como as três instituições trataram os setores e as questões agrárias surge como outro elemento importante na comparação. Enquanto a FIEL fez uma opção preferencial pelos setores dominantes no campo desde o primeiro momento, como demonstra o fato de que uma de suas quatro corporações fundadoras era a SRA, as outras duas entidades analisadas, IPÊS e FM, manifestaram um tratamento diferente a esses grupos.

No caso da FM, quase não se registraram sócios representativos desse tipo de atividade, a não ser por algumas indústrias que fizeram encadeamentos com a produção primária. Além disso, as temáticas vinculadas a esse setor despertaram pouco interesse entre seus intelectuais, constituindo-se em seu ponto fraco nos momentos que lhes tocou assumir cargos de condução no Estado.

Em contrapartida, o IPÊS resolveu tomar partido nas disputas internas dentro do setor, inclinando-se pelos interesses modernizadores no campo em contraposição aos tradicionais, ainda que essa opção aparecesse mais claramente na regional carioca e sofresse maior resistência na paulista, vencendo finalmente a primeira, cujos técnicos apresentaram propostas de reforma agrária um tanto ousadas para o meio empresarial e conduziram vários órgãos estatais encarregados de implementá-la.

A relação entre o capital nacional e o capital estrangeiro também foi uma das diferenças importantes entre os casos. Tanto o IPÊS quanto a FIEL mantiveram uma elevada participação em seu quadro societário de empresas e representantes do capital estrangeiro. No entanto, a FM, mesmo tendo permitido a participação dessas empresas como sócios ativos e aderentes, restringiu essa intervenção apenas a essas duas categorias, barrando seu acesso ao grupo de sócios fundadores, com poder para conduzir a entidade.

Dessa forma, pode-se perceber tanto o teor ideológico que os membros fundadores queriam imbuir à entidade, quanto certos temores não declarados que provavelmente os afligiam. As 
empresas associadas inicialmente pela FM eram pequenas e médias indústrias que sofriam a concorrência do capital transnacional e associado, tendo fundado a organização para se opor aos privilégios concedidos a esses grupos. Assim, sabendo-se mais fracos que eles, no momento em que começavam sua expansão, introduziram algumas salvaguardas nos estatutos para garantir a manutenção de seu controle interno.

Enquanto isso, as outras duas entidades não se preocupavam inicialmente com essa questão, já que elas congregavam representantes da elite empresarial e seus objetivos eram diferentes, isto é, representavam o grosso da grande burguesia, tendo em vista enfrentar o crescente conflito social, ainda que pudessem surgir desavenças particulares entre algumas de suas frações.

As divergências da FIEL em relação à organização de cúpula do setor industrial manifestaram-se nos momentos em que essa fração mais concentrada dentro da indústria perdeu o comando da entidade corporativa; circunstância que provocou, concomitantemente, uma reacomodação quanto às suas posições ideológicas, afastando-se a UIA, sob nova orientação, de seus compromissos anteriores e não a situação inversa.

Além disso, a participação de militares, representando setores ou individualmente, foi outra das características comuns aos três casos analisados, ainda que no do brasileiro tenha sido, sem dúvida, a de maior destaque. Diferença que pode estar associada tanto ao caráter dos empresários quanto dos militares.

Nesse caso, observamos que os governos impulsionaram uma forte interação estratégica entre setores civis e militares, possibilitando uma profunda imbricação entre os interesses da burguesia local com os do Estado e os das Forças Armadas. Dessa forma, outorgava-se a cada um desses agentes papéis relevantes no desenvolvimento econômico nacional, o que unicamente era possível mediante um esforço conjunto. Essa era uma característica 
Institutos de Estudos Econômicos de Organizações...

que, no Brasil, seria potencializada e, inclusive, institucionalizada com a criação da Escola Superior de Guerra (ESG).

Devido a tradições diferentes, os militares argentinos estiveram mais afastados dos empresários, exceto em casos isolados, e sua cúpula não desenvolveu uma consciência desenvolvimentista, semelhante à brasileira, ainda que sob seu comando estivessem empresas estatais de porte, funcionando o complexo industrialmilitar com maior autonomia, sujeito mais a noções de soberania do que de desenvolvimento nacional.

Essa característica foi reforçada pelas divisões existentes nas próprias Forças Armadas argentinas e pelos relacionamentos dos empresários com suas diferentes linhas internas. Assim, enquanto a alta burguesia, representada pela FIEL, relacionava-se de forma estreita com os "senhores da guerra", militares com comando de tropa e maior poder na estrutura hierárquica, eram perceptíveis certos atritos com os "burocratas", aqueles que faziam carreira à frente de organismos e empresas estatais (Canelo, 2005). Porém, estes apenas tardiamente tenderam a estabelecer alianças mais sólidas e estruturadas com outras frações representativas do capital, principalmente com aquelas encarnadas pela FM, e sempre perderam nas disputas de longo prazo para os primeiros.

Essa forma diferente de desenvolvimento estatal entre Brasil e Argentina marcou outra de suas características distintivas, já que permitiu ao primeiro país contar com uma burocracia mais vasta, recrutada meritocraticamente e com maior permanência nos cargos, assim como com aparelhos estatais mais amplos e coerentes, que se traduziram numa maior capacidade administrativa, fazendo-o menos dependente do fornecimento e das intromissões externas (Sikking, 1991 e 1993).

Contudo, as organizações não foram capazes de progredir apenas cooptando uma quantidade apreciável de membros; elas também tiveram que os fazer partícipes de suas atividades como uma forma de se sobrepor a sua inclinação por maximizar ganhos 
individuais, fugindo de compromissos coletivos para minimizar suas inversões nesse tipo de ações (Olson, 1982), logo que fosse afastado o perigo iminente que os tinha compelido a participar mais ativamente.

No entanto, essa participação não era horizontal. Existiam distintos gêneros de compromissos, os quais podiam respeitar escalas hierárquicas anteriores de tipo familiar, étnicas, geracionais, poder econômico e de prestígio social, em sentido amplo. Assim, estabelecia-se uma pirâmide cuja cúpula tendia a se perpetuar no comando das instituições, podendo, inclusive, manter-se até quando a base começasse a ruir.

Dessa forma, o papel desempenhado por minorias ativas dentro das instituições tornou-se outra de suas características comuns, destacando-se a ação do que podemos qualificar como verdadeiros pais fundadores. Eles manifestaram-se como os artífices e impulsores iniciais desses empreendimentos, nucleando em seu entorno um punhado de homens que conjuntamente cristalizaram um corpo dirigente extremamente estável que as comandaram por prolongados períodos.

Embora essas minorias se revelassem importantes na hora de consolidar a estrutura de uma organização, com o passar do tempo podiam transformar-se em empecilhos que dificultariam sua renovação e adequação aos novos tempos, ossificando-as (Michels, 1996). Esse entrave revelou-se fatal no caso do IPÊS, já que seu corpo dirigente mostrou-se incapaz de se adequar à nova realidade e tampouco experimentou variações significativas na sua composição. Praticamente a maior parte das modificações estruturais que se produziriam na entidade não obedeceu a razões de crescimento e sim de enxugamento, provocado tanto pela cisão das seccionais, em 1964, posteriormente, quanto pela extinção de organismos internos.

No caso da FIEL, produziram-se algumas incorporações pontuais que lhe permitiram fazer transformações menores em sua 
Institutos de Estudos Econômicos de Organizações...

estrutura, tendo como propósito adequá-la a mudanças ocorridas no cenário empresarial e político, assim como reposições naturais no seu quadro societário, mantendo o perfil das novas filiações basicamente similar àquele estabelecido inicialmente.

Quanto à FM, seu comportamento foi bastante particular, existindo extensos períodos de relativa calma organizacional, intercalados por cortes abruptos, ainda que sempre conduzidos por uma tríade dirigente, cujo comportamento empresarial e associativo revelou-se bastante versátil. Sua cúpula demonstrou ser capaz de adequar tanto suas características quanto as de seus membros e dirigentes de acordo com as exigências que lhe demandava cada período pelo qual atravessavam.

Os integrantes dessas organizações tinham objetivos definidos que implicavam no desenvolvimento de diversas atividades para sua consecução. Diferentemente das organizações corporativas, elas utilizaram em sua forma de agir uma nova gama de ações, que seu caráter mais privado e sua maior homogeneidade ideológica entre associados permitiram.

Como o conflito ideológico converteu-se numa das frentes de batalha mais importantes dessa época, a construção de um discurso mais ou menos homogêneo, que legitimasse as pretensões de grupo, foi uma de suas tarefas primordiais. Mediante esse mecanismo, os empresários podiam apresentar seus interesses particulares como se fossem de interesse geral e, assim, justificá-los, possibilitando, dessa forma, uma construção hegemônica.

Os modos como essas entidades realizaram suas articulações foram abordados por meio da análise de fontes inéditas e editadas. Entre as primeiras, incluímos principalmente atas correspondentes aos seus diferentes órgãos diretivos, balanços, cartas, informes, relatórios e outros documentos existentes no Arquivo Nacional, tanto no acervo específico como no de Paulo Assis Ribeiro, para o IPÊS e atas do Comité Ejecutivo para a FM. Entre as fontes publicadas, recorremos às próprias das entidades, assim como 
a publicações periódicas diversificadas. No primeiro caso, Boletim Mensal do IPÊS, Notícias do IPÊS/SP e Boletim Informativo Mensal, Informativo, Noticiário, os três do IPÊS/Gb; Indicadores de Coyuntura para FIEL, e Análisis de la Coyuntura, Estúdios, Newsletters, Novedades Econômicas e PAL para a FM. Através delas, estudamos a natureza do discurso das instituições, particularmente acerca dos temas que consideravam prioritários, as reivindicações em torno deles e o modo como esses estavam sendo tratados por outros interlocutores.

Diferentemente dos outros dois institutos, no caso do IPÊS conseguimos avançar mais solidamente na análise do modo como conduziram suas finanças. Para tanto, contamos com os Livros Diários do IPÊS/Rio, correspondentes aos anos de 1962 e 1963, e vários balanços editados, mimeografados ou rascunhados ${ }^{6}$. Esses, embora não sejam totalmente fiéis, nos oferecem claros indícios de numerosos aspectos de suas atividades financeiras.

Mediante esses dados, observamos que as organizações tomaram a luta ideológica como um aspecto central do confronto social e passaram a se pensar como um baluarte nesse sentido. Tal necessidade era decorrente das dificuldades que os empresários tinham para realizar por si mesmos uma tarefa desse tipo e a inadequação das entidades corporativas para esse fim, já que se encontravam demasiado presas e identificadas com a defesa de interesses particulares e conflitos internos.

Como a produção de conhecimento especializou-se em níveis que demandavam a participação de pessoal específico, que pudesse dar conta dessa atividade, as organizações precisaram dos serviços de/ou da capacitação de um conjunto de indivíduos tecnicamente competentes para traduzir as necessidades e os desejos dos empresários como enunciados cientificamente aceitos e, dessa forma, dar-lhes um marco de legitimidade, assumindo, caso fosse necessário, sua implementação. Assim, os tecnocratas passaram a ocupar um lugar central na elaboração do discurso e até das práticas políticas cotidianas, convertendo-se o especialista num 
Institutos de Estudos Econômicos de Organizações...

elemento-chave que foi substituindo, paulatinamente, o burocrata tradicional.

Nas três entidades deu-se uma inter-relação simbiótica entre empresários e intelectuais, na qual cada um interveio pondo à disposição da organização seu capital disponível, em óbvia referência a Bourdieu (1989), ainda que a delimitação de tarefas entre eles não seja tão clara no começo e fosse manifestando-se, posteriormente, com maior nitidez para os casos argentinos. Contudo, uma diferença importante se adverte entre os casos nacionais. Enquanto, de forma geral, a FIEL e a FM contrataram pessoal recém formado e investiram pesadamente em sua capacitação, o IPÊS vinculou-se a intelectuais consagrados, usufruindo de suas capacidades técnicas sem realizar nenhum esforço em seu aprimoramento individual.

Essa construção foi difícil, experimentando avanços e recuos, mas tendo um norte claramente definido. De forma geral, podemos apontar pelo menos dois períodos. O primeiro deles caracterizou-se pela construção de um discurso amplo, imbricando diferentes fontes de legitimação, e o segundo foi dominado principalmente pelo discurso racionalista, sob viés economicista, que dispensava outras fontes de legitimação.

Assim, podemos entender melhor alguns eventos que separadamente não possuem o mesmo sentido, como, por exemplo, a participação da Igreja em atividades do IPÊS e o inicial apelo religioso na FM, ainda que não encontremos algo parecido na FIEL. Dessa maneira, percebe-se que a construção discursiva e as práticas políticas na área econômica por parte desses institutos de pesquisa não foi algo isolado, mas sim que se encontram integrados a uma construção muito mais ampla, com múltiplas interações que as reforçaram. A defesa da propriedade privada, por exemplo, encontrava-se inserida na custódia da cultura nacional, de caráter ocidental e cristão, por oposição ao comunismo, de fundamentos ateus e internacionais.

Anos 90, Porto Alegre, v. 13, n. 23/24, p.179-214, jan./dez. 2006 
É interessante observar também que a invocação cristã não incluiu nenhum outro qualificativo que fizesse alusão alguma às distintas vertentes nas quais essa crença milenar encontra-se dividida. Assim, ela serve como gigantesco "guarda-chuva" que pôde abrigar tanto as variantes católicas, autoproclamadas majoritárias no Brasil e na Argentina, quanto as protestantes, predominantes nos Estados Unidos e noutros países capitalistas avançados. Desse modo, limitava-se habilmente algum tipo de atrito que pudesse surgir nesse sentido e mantinha-se aberta a possibilidade de receber e dar colaboração de/a ambos os lados.

Em contrapartida, a ala conservadora católica manteve relações fluidas com esse tipo de organizações e participou ativamente da vida política como propaladora de idéias favoráveis a uma ordem capitalista com um tom mais humanitário, como forma de contenção do comunismo, inclusive alentando e legitimando os golpes de Estado.

Unido ao apelo às tradições cristãs, também esteve a invocação à nação, seja de forma expressa, no caso da FM, ou tácita, no caso do IPES. Mediante esse recurso discursivo, os interesses particulares podiam ser apresentados como de interesse geral. Quimera inatingível que funcionava perfeitamente como a principal fonte de legitimação da ordem social e da solidariedade entre as classes no modo de produção capitalista (Hobsbawm, 1990).

No entanto, esses dois recursos de legitimação foram se diluindo com o passar dos anos, fosse por sua substituição por outros discursos ou pelo paulatino distanciamento evidenciado por parte da hierarquia católica em relação aos governos autoritários e às políticas econômicas que os sustentavam. Assim, na década de oitenta e, com maior força, na década de noventa, a linguagem dos economistas ganhou sustento próprio, prescindindo de outros discursos que a legitimassem.

A adoção do keynesianismo, que apregoava a utilização do gasto estatal como veículo para manipular o desempenho das 
Institutos de Estudos Econômicos de Organizações...

economias nacionais, demandou o desenvolvimento de complexos modelos que necessitaram pessoal técnico especializado para sua elaboração. $\mathrm{O}$ fracasso do estado de bem-estar nos anos setenta não significou um retrocesso nessa tendência, já que catapultou, ao centro da cena, teorias monetaristas com elaborados modelos matemáticos que novamente requeriam economistas que os interpretassem adequadamente (Montecinos, 1998; Markoff; Montecinos, 1994).

Também as tramas internacionais das finanças e agências de cooperação tornavam-se cada vez mais complexas, sendo os países e suas elites tecnocráticas submetidos a exaustivos monitoramentos e táticas de disciplinamento para ingressar ou se manter em determinados programas (Corvalán, 2002), nos quais os organismos governamentais e até mesmo fundações privadas norte-americanas, que funcionavam como aparelhos quase estatais, desempenhavam um papel predominante, constituindo essa inclinação outra das semelhanças que despontou na pesquisa.

As atividades desse tipo de organizações são abundantes durante a década de sessenta, possivelmente alentada pelo temor de que a Revolução Cubana se espalhasse por todo o subcontinente, sobressaindo-se a Embaixada Americana e o Council for Latin American (CLA), com a figura de Nelson Rockefeller num primeiro plano, como desencadeadores de muitas iniciativas e brindando apoio ideológico e financeiro a diferentes instituições, entre as quais o IPÊS e a FIEL que aparecem no início como claramente favorecidos.

No entanto, para o final da década, particularmente depois de 1968, esses impulsos decresceram paulatinamente e tenderam a mudar de características, passando a assistência a ser fornecida por parte de vários fundos de financiamento de pesquisas, com uma aparência mais neutra, ou organismos internacionais, nos quais a presença visível do "colosso do norte" se dilui, mas não a força de sua ação "invisível". Essa mudança de estratégia poderia 
obedecer ao fato de que o comprometimento de uma ajuda direta seria demasiado perigoso, já que deixaria muitas evidências que poderiam ser usadas por grupos opositores para alentarem ainda mais o sentimento antiamericano.

O trânsito rotineiro por universidades estrangeiras, particularmente norte-americanas, passou a desempenhar uma função semelhante, despontando claramente para o caso argentino ainda na década de setenta, tanto em relação à FIEL quanto à FM, e que se intensificou de maneira notável na década de oitenta. Embora esse seja quase que um requisito indispensável nas trajetórias dos intelectuais vinculados a essas duas organizações, no caso do IPÊS esse percurso não apareceu com a mesma força, mas sim para outras organizações que lhe sobreviveriam (Loureiro, 1994).

Entretanto, o deslocamento da tecnocracia, como agente, para um local central colocava um problema de vital importância. Devido ao fato de que suas origens sociais podiam ser diferentes das da classe dominante, era necessário construir ligações que assegurassem sua obediência, impedindo que esses agentes ganhassem ares de liberdade. Em princípio, os golpes militares, pelo uso da força, afastaram essa possibilidade. Mas, a reconstituição do consenso, a longo prazo, iria requerer novas formas de engajamento.

Quanto à relação com o Estado, na segunda hipótese, apresentaram-se as maiores dificuldades teóricas e metodológicas da tese, já que, no melhor dos casos, da ação dos grupos de pressão ficam registrados apenas os resultados e não os procedimentos pelos quais se chegaram a eles. Por isso, nossa pesquisa esteve centrada na realização de um amplo rastreamento cruzando dados, tanto de pertencimento dos membros das organizações, registrado nas listas anteriores e das provenientes de publicações empresariais e jornais, quanto dos originados de entrevistas próprias e outras existentes em diferentes acervos ou já editadas. 
Institutos de Estudos Econômicos de Organizações...

Entre as primeiras, aproveitamos as realizadas com José Ignacio Castro Garayzábal, secretário executivo da FM e seu único impulsor vivo; Ángel Manzur, ex-deputado provincial e vicepresidente da Democrácia Cristiana (DC); Rafael Vaggione, advogado e ex-deputado provincial justicialista; e Juan Carlos Maqueda, ex-operador de José Manuel de la Sota e o segundo na chefia de Gabinete no início da gestão de Jorge Rodríguez, no momento da renúncia de Domingo Cavallo como ministro de Economia.

Das segundas, temos utilizado algumas existentes nos arquivos do CPDOC, da FGV e da Universidad Torcuado Di Tella. Do primeiro repositório, utilizamos as entrevistas dadas a Dênio Chagas Nogueira, Octávio Gouvêa Bulhões e Jorge Oscar de Mello Flores; enquanto que do segundo tomamos duas entrevistas realizadas por Luis Alberto Romero a Alfredo Concepción e Guillermo Walter Klein (h) para o Proyecto de Historia Oral do Instituto Di Tella, antecessor do que viria a ser a Universidade. Também foram de utilidade seis entrevistas efetuadas por Eli Diniz e Renato Boschi (1978) para uma pesquisa acerca do empresariado brasileiro que, embora não identifiquem os entrevistados e sejam correspondentes a um período imediatamente posterior àquele por nós abordado, foram muito úteis para elucidar, de modo geral, o pensamento desse setor na época.

Baseando-nos nesses dados, pudemos observar que essas organizações utilizaram em sua atuação uma nova gama de ações, que foi possível devido a seu caráter mais privado e à maior homogeneidade ideológica entre seus associados. Dessa forma, ensaios de persuasão, gratificações, ameaças, montagens de crises e ações diretas foram seus recursos mais comuns.

Esses centros não eram contrários, por princípio, aos regimes democráticos. Embora tenham apoiado invariavelmente os golpes militares e muitos de seus membros estivessem a eles associados, sua oposição centrava-se essencialmente nas variantes populistas, que consideravam uma degeneração do sistema democrático, 
o qual era defendido e até alentado uma vez que, depurado, passasse a servir a seus interesses. Desse modo, a questão da forma como era exercida a representação política não se constituía no problema principal, mas sim os efeitos que ela provocava.

Assim, em momentos de aumento da confrontação entre diferentes atores sociais, essas tensões, depois de traduzidas ideologicamente, foram canalizadas em nível político, através de meios diretos de ação sobre os aparelhos de Estado, sendo os mais comuns a participação direta na luta eleitoral, em períodos democráticos, a utilização do parlamento em momentos em que ele funcionava, o alento a golpes de Estado e a provisão de membros diretivos ou técnicos para ocupar postos importantes, que incluíram cargos de ministros e funcionários de relevância nas pastas da área econômica e cadeiras nos diretórios das principais empresas e bancos estatais.

Uma das conseqüências mais importantes de sua ação foi a colonização de diversos aparelhos de Estado por interesses de grupos, ainda que amplos e, por vezes, despersonalizados, produzindo-se, quase que literalmente, uma "privatização" das instituições estatais. Desse modo, o bloco de poder, liderado por alguns desses institutos, reorganizava ou tentava reorganizar o Estado e, sob seu controle, recompor sua própria posição.

No caso do IPÊS, pessoas a ele vinculadas estiveram presentes, após 1964 e durante toda a ditadura, à frente da Casa Civil e da Casa Militar, do SNI, dos ministérios da Fazenda, do Planejamento, da Indústria e Comércio, do Ministério Extraordinário para Coordenação dos Órgãos Regionais e, esporadicamente, nos da Justiça e do Trabalho e Previdência Social, assim como em inúmeros órgãos dependentes desses e outros ministérios, bancos e empresas estatais e, posteriormente, chegaram à Presidência do país dois generais vinculados ao Instituto, Ernesto Geisel e João Baptista Figueiredo. 
Institutos de Estudos Econômicos de Organizações...

No que diz respeito à FIEL, ainda antes de sua criação, vários de seus membros atuaram como ministros da Economia entre 1961 e 1963 e, uma vez em funcionamento, preencheram esse cargo em todas as ditaduras militares argentinas, de 1966 até 1969 e de 1976 até 1983, exceto no curto interregno do governo do general Roberto Levingston.

Essa participação também aconteceu em menor medida em tempos democráticos, mediante esporádicas incursões no começo do governo Menem e na presidência de Fernando de la Rua, entretanto ocupando a pasta da Defesa e, fugazmente, a de Economia. Além desse posto, também outros membros foram presidentes e vice-presidentes do BCRA em diversas administrações.

Dessa forma, levando em consideração unicamente esses cargos, observamos que a presença dos homens da FIEL em postos-chave dentro do governo chegou a ser esmagadora em momentos importantes da história argentina, preenchendo-os entre 1960 e 1962, circunstância que tornaria a se repetir nas duas mudanças internas ocorridas durante o conflituoso ano de 1981, considerado de transição para o governo militar, e também em 1989, momento em que a economia argentina mergulhou numa das piores crises de sua história recente.

No caso da FM, sua incursão foi menor e mais concentrada temporalmente. Cavallo ocupou fugazmente a presidência do BCRA em 1982, foi chanceler entre 1989 e 1991 e ministro da Economia entre 1991 e 1996 e novamente em 2001, sendo mais visível a colonização dos aparelhos de Estado por membros da FM entre 1989 e 1996.

Contudo, apesar dessa maciça ocupação, muitas vezes podia existir certa incoerência na manutenção dessas alianças num mesmo intervalo temporal. Tal comportamento deu-se particularmente na Argentina e foi diferente do caso brasileiro, no qual o IPÊS alcançou rapidamente a hegemonia no momento de preencher os cargos na área econômica e conexas, embora as diferenças se 
transladassem agora ao seio do próprio IPÊS, com a disputa entre as seccionais paulista e carioca.

No caso argentino, isso obedecia ao fato de que os partidos políticos passaram a se constituir apenas em máquinas eleitorais, mostrando-se ineficientes como órgãos de governo. Eles concentraram todo o seu esforço em conquistar adesões, cada vez mais esquivas à medida que a crise se acentuava, prestando pouca atenção à formulação de programas de governo e equipes preparadas com as quais pudessem preencher os cargos demandados pela estrutura estatal uma vez no poder. Se por ventura os partidos chegavam ao governo, tinham de sair rapidamente a sua procura, aceitando as ofertas de mercado, cuja abundância e qualidade muitas vezes não eram das mais apropriadas.

Essa situação representava a predominância de um determinado mecanismo de controle das decisões estatais, na qual diferentes grupos, que baseavam seu poder na defesa de interesses materiais-ideológicos, apropriavam-se sucessivamente dos aparelhos estatais. Não obstante, a luta entre esses grupos podia levar à sua colonização parcial e simultânea, impondo, na prática, uma conflituosa convivência, e unicamente em condições particulares esses cargos eram ocupados hegemonicamente. Dessa forma, comandar um instrumento como o BCRA representava um interesse especial. Ele podia transformar-se num importante contrapeso ao ministro da Economia, ao adotar ações independentes, ou constituir um apoio inestimável para levar adiante seus programas econômicos.

Finalmente, com o passar do tempo e à medida que as tensões enunciadas diminuíam e que a classe dominante recompunha sua hegemonia, sustentamos, como contra-hipótese, que o controle dos aparelhos de Estado tenderia a se realizar através de maneiras indiretas, voltando o seu controle às mãos de políticos, ditos profissionais, ou de burocratas com vinculações menos diretas, enquanto que os empresários canalizariam novamente sua ação 
Institutos de Estudos Econômicos de Organizações...

pela via das organizações corporativas de velho cunho. Assim, as atividades das classes dominantes "tornadas Estado" passavam novamente a estar encobertas, dissimuladas e transfiguradas, assegurando a transubstanciação das relações de força, transformando a violência que elas encerravam objetivamente em poder simbólico (Bourdieu, 2000, p. 72).

Essa tendência é mais evidente para o caso brasileiro. $\mathrm{Na}$ Argentina, foi interrompida várias vezes, tanto por governos autoritários quanto democráticos, prolongando-se esses ciclos até a atualidade, demonstrando com isso as dificuldades para consolidar um rumo político que outorgue ao país certa estabilidade.

Tal hipótese tornou-se a de mais difícil demonstração, tendo que admitirmos a necessidade de adequá-la frente ao fato de não podermos comprová-la totalmente, assim como introduzir-lhe uma maior complexidade a fim de responder nosso interrogante com um pouco mais de exatidão. Embora seja verdade que o IPÊS tenha entrado em crise em 1967, momento em que a economia brasileira "entrava" nos trilhos que iriam desembocar no "Milagre Econômico", que, por sua vez, conduziu ao paulatino restabelecimento da hegemonia exercida pela burguesia, liderada incontestavelmente pela ala paulistana, é igualmente certo que ainda existiam conflitos importantes dentro da sociedade, sobretudo aqueles que se expressavam no interior das classes dominantes, circunstância que poderia nos explicar a sobrevivência por mais tempo do IPÊS/GB em relação ao IPÊS/SP.

Esse comportamento assemelha-se mais ao ocorrido na Argentina do que acreditávamos inicialmente. Nesse país, também a burguesia passou a gozar de um amplo domínio a partir de 1976 e os conflitos mais relevantes no âmbito da contenda ideológica por determinar políticas econômicas deslocaram-se da luta entre as classes a uma maior disputa intraclasse, como tentamos provar com a explicitação das diferenças entre FIEL e FM, e inclusive com as divergências que se deram no interior dessas instituições. 
A resposta para esse contraste no tempo de vida dos institutos deve-se fundamentalmente às diferenças observadas no interior dessas instituições do que a condicionantes externos. $\mathrm{O}$ impulso para seu surgimento provinha dos conflitos existentes na sociedade, que ameaçavam as posições dos grupos que lhe dariam vida, e a tendência geral foi a de diminuir seu compromisso coletivo à medida que as tensões se dissipavam.

Assim, as razões do maior ou menor êxito na sobrevivência dessas instituições deram-se pela forma como elas souberam aproveitar esse impulso inicial, criando uma estrutura que fosse capaz de substituí-lo quando esse começasse a fraquejar, encontrando novas finalidades a perseguir. Dessa forma, a decadência acontecia quando os objetivos das entidades eram alcançados, sem que os antigos fossem substituídos adequadamente por outros novos que mantivessem o potencial de convocatória, decrescendo, a partir de então, o recrutamento de membros e recursos que, apesar dos esforços de seus dirigentes, agora não alcançavam compensar totalmente os que saíam, podendo esses afastamentos estar motivados por questões de ordem natural, como mortes e aposentadorias, desgaste ou colisão de interesses.

Em relação a esse ponto, estabelece-se uma das diferenças mais visíveis entre o caso brasileiro e os argentinos. Enquanto o IPÊS entrou em decadência pouco depois de alcançar seu objetivo mais importante, a FIEL e a FM conseguiram se sobrepor a numerosas dificuldades, estabilizando uma estrutura organizacional por um período mais prolongado. Esse contraste deve-se, em nosso entendimento, fundamentalmente ao fato de que o Instituto brasileiro não conseguiu transformar seu perfil para adequá-lo às novas circunstâncias.

Por isso, no caso do IPÊS, a produção ideológica ficou severamente limitada entre 1966 e 1967, a não ser em relação a questões isoladas, como a educativa, encontrando o Instituto enormes dificuldades para competir de forma eficaz com outros centros de 
Institutos de Estudos Econômicos de Organizações...

pesquisas, principalmente pelo fato de não contar com uma direção especializada que definisse estratégias adequadas e ao êxodo para cargos oficiais de seus mais importantes intelectuais, sem que conseguisse substituí-los por novas cooptações ou formação de novos quadros, imprescindíveis a uma política de longo prazo.

Nos casos argentinos, a emergência de uma estrutura hierárquica separada, composta exclusivamente por intelectuais, incidiu para que esses institutos mantivessem seu fôlego após o impulso inicial, assim como destruíssem ou sucateassem organismos estatais concorrentes no momento que passavam a ocupar cargos oficiais, como forma de garantir sua reprodução. Diferentemente do acontecido com o IPÊS, esses intelectuais deviam fazer maiores inversões no sucesso das organizações que os patrocinavam já que, distintamente dos empresários, suas possibilidades fora desses centros eram mais limitadas, circunstância que lhes aconselhava adotar estratégias de sucessão antes que de subversão.

A possibilidade de cristalizar uma estrutura interna mais autônoma por parte dos intelectuais agrupados nessas organizações seria a razão fundamental para explicar o fenômeno. Diferentemente dos empresários, que para sua existência pessoal podiam prescindir tranquilamente desses institutos, os intelectuais tinham motivos materiais mais concretos para garantir seu funcionamento.

Nesse segundo momento, o discurso racionalista, sob o viés economicista, ganhou consistência própria, tendência comprovada também em diferentes países e que estava vinculada ao fato de que a análise econômica não possuía apenas um papel significativo na procura de soluções dos problemas técnicos dos Estados, mas também na elaboração de suas políticas, por meio de uma linguagem que lhes conferisse legitimidade. Os governos, ao cumprirem com o ritual correto, nomeando prestigiosos economistas para redigirem os novos programas e formular as desculpas pelo fracasso dos anteriores, curvavam-se, assim, frente à importância 
retórica do discurso dos expertos, podendo tornar altamente institucionalizada essa propensão de transferir aos possuidores de conhecimentos técnicos as responsabilidades sobre problemas difíceis de resolver.

No entanto, em virtude de sua ascensão no governo e na rede de relações interestatais, os expertos, além de atuarem como legitimadores, encontram-se também em condições de definir as próprias realidades políticas. Uma vez que a necessidade técnica foi aceita, ela pôde servir de justificativa para práticas promovidas com outros propósitos e atingir outras áreas de interesse, já que, à medida que eles se faziam fortes, tratavam de redefinir também áreas de outras agências governamentais de maneira tal que passassem à sua área de influência, transformando-se nos guardiões que influem sobre o destino dos recursos.

Dessa forma, a fala profissional dos economistas converteuse numa nova língua franca e o domínio desse recurso serviu também de estímulo para que os contatos e os valores profissionais se convertessem num fator significativo na escolha das pessoas que adotavam as decisões políticas nacionais. Embora essas escolhas se orientassem por padrões intelectuais, nos quais a dimensão acadêmica era a fonte mais importante de prestígio, e os economistas vissem-se a si mesmos a serviço da "racionalidade" ou da "eficiência", suas trajetórias podiam, e de fato estavam, determinadas por interesses particulares, especialmente com o aumento da complexidade do desenho e instrumentação das políticas públicas, que requeriam equipes entrosadas e não apenas indivíduos isolados, que demandavam enormes gastos para sua formação e manutenção.

Nesse sentido, também corre a predileção demonstrada pelas organizações estudadas em editar uma enorme quantidade de textos, apresentados em diferentes formatos, como panfletos, livros, revistas, jornais ou encartes, demonstrando a necessidade de construir um consenso através desses ensaios de persuasão 
Institutos de Estudos Econômicos de Organizações...

(Meynaud, 1963), mesmo durante regimes autoritários. Desse modo, mediante a difusão de materiais impressos, as idéias podiam espalhar-se consideravelmente no espaço e no tempo, atingindo um público mais amplo. Contudo, esse não era seu único objetivo. Concomitantemente, uma vez que as idéias eram objetivadas num texto impresso, esse ato lhes conferia verossimilhança e, assim, as legitimava.

O IPÊS iria mais longe nessa direção, empregando sistematicamente recursos audiovisuais, reconhecendo com isso a importância que eles adquiriam no mundo moderno nessa tarefa, apelando ao cinema, ao rádio e à televisão para atingir as grandes massas, inclusive as pertencentes às camadas populares. Essa diferença não foi marcada apenas por inclinações particulares dos institutos, porém, em todo caso revelaram a profundidade do conflito social e até onde era necessário comprometer-se no embate político, já que as frentes de batalha eram das mais variadas.

Essa circunstância também levou, de forma comum, os três institutos a se preocuparem com a temática educativa como um todo, promovendo estudos e propostas de reformulação dos sistemas de ensino em um sentido mais abrangente, talvez como forma de garantir a reprodução ampliada das sociedades e, por conseguinte, de si próprios, herdando desse processo, em grande parte, os sistemas atualmente vigentes.

Recebido em 20/05/2006.

Aprovado em 14/08/2006.

Institutes of economic studies in organizations and their relations to State in a comparative view: Argentina and Brazil, 1961-1996

Abstract: This paper is the syntheses of the principal conclusions of my thesis, which shows the constitution and the ways of acting of three economy research centers, financed by company groups, which most prominent members have reached the economy leadership. They have occupied important administrative posts in Brazil and in Argentina, from 1961 to 1996.

Anos 90, Porto Alegre, v. 13, n. 23/24, p.179-214, jan./dez. 2006 

Institutos de Estudos Econômicos de Organizações...

de classe social e não como numa categoria exterior a ela, representando uma divisão em relação à distribuição do poder político e à superestrutura ideológica.

${ }^{6}$ Correspondentes aos anos de 1962 e 1963 para o IPÊS e o IPÊS/Rio; e 1967, primeiro semestre de 1968 e 1969 para o IPÊS/GB.

\section{Referências}

ASSIS, Denise. Propaganda e cinema a serviço do golpe: 1962-1964. Rio de Janeiro: Mauad/ Ed. da FAPERJ, 2001.

BIRLE, Peter. Los empresarios y la democracia en la Argentina: conflictos y coincidencias. Buenos Aires: Editorial de Belgrano, 1997.

BOURDIEU, Pierre. Intelectuales, política y poder. Buenos Aires: EUDEBA, 2000. . O Poder Simbólico. Rio de Janeiro: Bertrand Brasil, 1989.

CAMOU, Antonio. De como las ideas tienen consecuencias. Analistas simbólicos y usinas de pensamiento en la elaboración de la política económica argentina (1983-1985). Tese de doutorado, FLACSO, México, 1997.

CANELO, Paula. La política contra a economía: los elencos militares frente al plan económico de Martínez de Hoz durante el proceso de Reorganización Nacional (1976-1981). In: PUCCIARELLI, Alfredo (coord.). Empresarios, tecnócratas y militares. La trama corporativa de la última dictadura. Buenos Aires: Siglo XXI, 2004.

CORVALÁN, María Alejandra. El Banco Mundial. Intevención y disciplinamiento. El caso argentino, enseñanzas para América Latina. Buenos Aires: Biblos, 2002.

DE PABLO, Juan Carlos. Apuntes a mitad de camino (economía sin corbata). Buenos Aires: Ediciones Macchi, 1995.

. Mi paso por FIEL. Indicadores de Coyuntura, FIEL, edición especial $30^{\circ}$ aniversario, n. 333, p. 75-85, abr. 1994.

DINIZ, Eli; BOSCHI, Renato Raul. Empresariado Nacional e Estado no Brasil. Rio de Janeiro: Forense Universitária, 1978.

DREIFUSS, René Armand. 1964: A conquista do Estado. Ação Política, Poder e Golpe de Classe. Petrópolis: Vozes, 1981.

EAGLETON, Terry. Ideologia. São Paulo: Boitempo/UNESP, 1998. 


\section{Hernán Ramírez}

GOULNER, Alvin. La dialéctica de la ideología y la tecnología. Los orígenes, la gramática y el futuro de la ideología. Madrid: Alianza Editorial, 1978.

GRAMSCI, Antonio. Los intelectuales y la creación de la cultura. Buenos Aires: Nueva Visión, 1987.

HEINZ, Flavio M. (Org.). Por outra história das elites. Rio de Janeiro: FGV, 2006.

HOBSBAWM, Eric. Nações e nacionalismo desde 1780. Rio de Janeiro: Paz e Terra, 1990.

LOUREIRO, Maria Rita. Os economistas no governo: gestão econômica e democracia. Rio de Janeiro: FGV, 1994.

MARKOFF, John; MONTECINOS, Verónica. El irresistible ascenso de los economistas. Desarrollo Económico, v. 34, n. 133, abr./jun. 1994.

MARX, Karl. Contribución a la crítica de la economía política. México: Editorial Cartago, 1983.

. El dieciocho Brumario de Luis Bonaparte. Barcelona: Ariel, 1971.

MEYNAUD, Jean. Los grupos de presión. Buenos Aires: EUDEBA, 1963.

MICHELS, Robert. Los partidos politicos. Buenos Aires: Amorrortu, 1996.

MILIBAND, Ralph. ElEstado en la sociedad capitalista. México: Siglo XXI, 1970.

MILLS, Charles Wright. La elite delpoder. México: Siglo XXI, 1979.

MONTECINOS, Verónica. Economics and Power: Chilean Economists in Government, 1958-1985. Pittsburgh: University of Pittsburgh, 1988.

N’HAUX, Enrique. Menem-Cavallo: el poder mediterráneo. Córdoba: El Corregidor, 1992.

OLSON, Mancus. The Logic of Collective Action. Cambridge, Massachusetts: Harvard University Press, 1982.

PUCCIARELLI, Alfredo. (coord.). Empresarios, tecnócratas y militares. La trama corporativa de la última dictadura. Buenos Aires: Siglo XXI, 2004.

RAMÍREZ, Hernán. Os institutos de estudos econômicos de organizações empresariais e sua relação com o Estado em perspectiva comparada: Argentina e Brasil, 1961-1996. Tese de Doutorado, PPG-História da UFRGS, Porto Alegre, 2005.

Anos 90, Porto Alegre, v. 13, n. 23/24, p.179-214, jan./dez. 2006 